\title{
DETERMINAN HIPERTENSI PRIMER PADA MASYARAKAT NON-ADVENT
}

\author{
I Gede Purnawinadi, Ranti Jesiy Pontoh
}

Fakultas Keperawatan, Universitas Klabat, Airmadidi-Minahasa Utara 95371, Indonesia

E-mail: purnawinadi87@unklab.ac.id

\begin{abstract}
Abstrak
Secara global hipertensi merupakan penyebab kematian utama dari total semua kematian. Hipertensi belum diketahui penyebab pastinya, tapi hal yang dapat dilakukan adalah dengan menghindari faktorfaktor pencetus. Penelitian ini bertujuan untuk mengetahui faktor risiko yang berhubungan dengan kejadian hipertensi primer pada masyarakat Non-Advent. Jenis penelitian ini adalah kuantitatif dengan desain survei analitik melalui pendekatan cross sectional dan uji statistik yang digunakan Chi-Square. Jumlah sampel yang digunakan untuk mewakili populasi adalah 252 orang dengan menggunakan rumus slovin yang dipilih dengan teknik purposive sampling. Hasil uji statistik menunjukkan variabel usia $(p$ value $=0,000 ; \mathrm{OR}=7,590)$, riwayat keluarga $(p$ value $=0,001 ; \mathrm{OR}=2,401)$, dan obesitas $(p$ value $=0,000$ dan nilai $\mathrm{OR}=4,418$ ) memiliki hubungan yang signifikan dengan kejadian hipertensi dimana nilai $\mathrm{p}$ value $<0,05$, sedangkan jenis kelamin $(p$ value $=0,272 ; \mathrm{OR}=1,371)$, konsumsi kopi ( $p$ value $=0,503$; $\mathrm{OR}=1,236)$, merokok $(p$ value $=0,844 ; \mathrm{OR}=1,109)$, konsumsi alkohol $(p$ value $=0,986 ; \mathrm{OR}=1,058)$ tidak memiliki hubungan yang signifikan. Direkomendasikan untuk masyarakat agar memanfaatkan sebaik-baiknya ketersediaan tenaga atau pelayanan kesehatan, dengan tujuan melakukan pencegahan ataupun dalam hal menanggulangi masalah kesehatan dan untuk peneliti selanjutnya dapat menggunakan rancangan penelitian yang lebih lanjut seperti studi kasus kontrol dan studi kohort.
\end{abstract}

Kata Kunci: determinan, hipertensi primer, non-advent

\begin{abstract}
Globally hypertension is the leading cause of death of all deaths. Hypertension is not yet known the exact cause, but what can be done is to avoid trigger factors. This study aims to determine the risk factors associated with the incidence of primary hypertension in the Non-Adventist community. This type of research is quantitative with analytic survey design through cross sectional approach and statistical tests used Chi-Square. The number of samples used to represent the population is 252 people using the Slovin formula selected by purposive sampling technique. The results of statistical tests showed that the variable age ( $p$ value $=0.000 ;$ OR $=7.590)$, family history ( $p$ value $=0.001 ; O R=2.401)$, and obesity ( $p$ value = 0.000 and $O R$ value $=4.418$ ) had a significant relationship with the incidence of hypertension. where the $p$ value $<0.05$, while gender ( $p$ value $=0.272 ;$ OR $=1.371$ ), coffee consumption $(p$ value $=0.503 ;$ OR $=$ $1.236)$, smoking ( $p$ value $=0.844 ;$ OR $=1.109)$, alcohol consumption ( $p$ value $=0.986 ;$ OR $=1.058)$ did not have a significant relationship. It is recommended for the public to make the best use of the availability of health personnel or services, with the aim of doing prevention or in terms of overcoming health problems and for further researchers to use further research designs such as case control studies and cohort studies.
\end{abstract}

Keywords: determinant, non-adventist, primary hypertension. 


\section{Pendahuluan}

Kematian akibat penyakit tidak menular (PTM) terus menjadi salah satu tantangan pembangunan utama saat ini. Jumlah kematian PTM pada tahun 2015 sekitar 39,5 juta atau $70 \%$, dimana penyebab utama adalah penyakit kardiovaskular yaitu 17,7 juta atau $45 \%$ dari semua kematian (IFMSA, 2017). Salah satu penyakit tidak menular dikenal dengan tekanan darah tinggi atau istilah medis yaitu hipertensi. Hipertensi merupakan peningkatan tekanan darah abnormal yang dapat menjadi penyebab utama timbulnya penyakit kardiovaskuler (Ansar, Dwinata, \& Apriani, 2019). Penyakit hipertensi menimbulkan angka morbiditas dan mortalitas yang tinggi.

Secara global hipertensi merupakan penyebab kematian utama yaitu 7,1 juta atau $12,8 \%$ dari total kematian. Diperkirakan $70 \%$ orang yang mengalami serangan jantung dan $80 \%$ orang yang mengalami stroke sebelumnya memiliki riwayat hipertensi (Bell, Twiggs, Schappert \& Oli, 2015). Prevalensi hipertensi di Indonesia tahun 2013 pada penduduk yang berusia $\geq 18$ tahun berdasarkan diagnosis tenaga kesehatan sebesar 9,4\% dan berdasarkan pengukuran tekanan darah sebesar 25,8\% (Kemenkes, 2014). Menurut Riset Kesehatan Dasar (2013), pervalensi hipertensi tertinggi terdapat di Sulawesi Utara yaitu $27,1 \%$, sedangkan berdasarkan diagnosis ada $15 \%$. Prevalensi hipertensi tertinggi pada usia $\geq 18$ tahun menurut kabupaten atau kota di Sulawesi Utara, terdapat di Kepulauan Sitaro yaitu menurut pengukuran ada $35,7 \%$ dan yang terdiagnosa $18,7 \%$. Lebih lanjut di Kecamatan Tagulandang sendiri, berdasarkan data tahun 2013 di beberapa puskesmas Tagulandang ada sebanyak
$45-70 \%$ pasien yang terdiagnosa hipertensi (Kakalang, 2015).

Hipertensi yang lebih dikenal dengan darah tinggi menjadi perhatian dari semua kalangan masyarakat, terkait dampak yang ditimbulkannya baik dalam jangka pendek maupun jangka panjang sehingga membutuhkan penanggulangan jangka panjang yang menyeluruh dan terpadu (Kementerian Kesehatan RI, 2018). Penyakit hipertensi merupakan penyakit yang timbul akibat adanya interaksi dari berbagai faktor risiko (Oktaviarini et al, 2019). Gaya hidup seperti kebiasaan minum alkohol, durasi tidur tidak normal, stres kerja, dan lain sebagainya dapat menjadi faktor hipertensi (Wulandari, 2020). Sebagaimana penelitian yang dilakukan oleh Kakalang (2015) pada anggota Masehi Advent Hari Ketujuh menunjukkan faktor risiko usia, riwayat keluarga, konsumsi garam, konsumsi lemak jenuh, konsumsi jelantah, dan obesitas memiliki hubungan yang signifikan terhadap kejadian hipertensi. Penelitian yang dilakukan oleh Kakalang merekomendasikan pada penelitian selanjutnya jika ingin meneliti pada masyarakat yang non-Advent bisa ditambahkan variabel konsumsi alkohol, merokok, dan konsumsi kopi.

Berdasarkan studi pendahuluan yang peneliti lakukan, informasi yang dapatkan melalui wawancara dari beberapa masyarakat di Kabupaten Kepulauan Siau Tagulandang Biaro (SITARO) khususnya di Desa Tulusan Kecamatan Tagulandang yang mayoritas masyarakat disana adalah non-Advent mengatakan di setiap tahun ada beberapa orang meninggal karena penyakit tekanan darah tinggi dan serangan jantung. Berdasarkan uraian latar belakang yang telah dibahas, maka penelitian ini bertujuan untuk 
menganalisis determinan hipertensi primer pada masyarakat Non-Advent di Desa Tulusan Kecamatan Tagulandang. Metode

Jenis penelitian yang digunakan dalam penelitian ini adalah kuantitatif dengan desain survei analitik melalui pendekatan cross-sectional. Sampel dalam penelitian ini berasal dari 680 populasi masyarakat Non-Advent di Desa Tulusan Kecamatan Tagulandang melalui perhitungan rumus Slovin dengan hasil 252 orang, teknik menggunakan purposive sampling berdasarkan kriteria inklusi: semua masyarakat yang berusia $\geq 18$, bersedia menjadi partisipan dan menandatangani informed concent, dapat menulis dan berkomunikasi dengan baik, memiliki tempat tinggal yang tetap, dan masyarakat non-Advent. Sedangkan kriteria eksklusi adalah masyarakat yang berusia $<18$ tahun, tempat tinggal yang tidak tetap, menolak dalam partisipasi dalam penelitian ini, dan nggota Gereja Masehi Advent Hari Ketujuh. Pengumpulan data dan penyusunan laporan hasil penelitian dibuat mulai pada bulan September 2018 sampai dengan bulan Maret 2019.

Pertimbangan etika dalam proses pelaksanaan penelitian ini mencakup hak privasi untuk dilindungi, hak tidak disebutkan, hak untuk dirahasiakan, dan hak meminta pertanggung jawaban peneliti. Proses pengumpulan data diawali dengan diketahuinya data apa yang akan menjadi kebutuhan dalam pembuktian masalah setelah itu peneliti mengumpulkan data tentang populasi yang tersedia, selanjutnya ditentukan sampel penelitian untuk kemudian menjadi subjek penyebaran kuesioner. Pengumpulan data dilakukan dengan cara yaitu; melakukan pengukuran tekanan darah menggunakan alat sphygmomanometer aneroid dan auskultasi arteri menggunakan sthetoschope, serta akan melakukan pengukuran indeks massa tubuh responden. Menentukan seseorang menderita tekanan darah tinggi atau hipertensi perlu dilakukan beberapa kali pemeriksaan dengan tekanan darah 140/90 $\mathrm{mmHg}$ atau lebih tinggi (Anies, 2018). Pengumpulan data obesitas peneliti mengumpulkan data dengan menggunakan cara ukur indeks massa tubuh. Pengumpulan data faktor jenis kelamin, riwayat keluarga, kebiasaan merokok, konsumsi kopi dan konsumsi alkohol. Peneliti melakukan pengukuran secara langsung dengan menggunakan kuesioner kepada responden yang berisi pertanyaan.

Instrumen yang digunakan dalam penelitian ini adalah alat pengukur tekanan darah Sphygmomanometer aneroid dan Sthetoschope digunakan untuk mengukur tekanan darah partisipan yang dilakukan oleh peneliti, alat ukur berat badan (timbangan), alat ukur tinggi badan (microtoise) serta alat tulis menulis berupa pulpen dan buku catatan untuk hasil pengukuran tekanan dan IMT, laptop, informed consent (lembar persetujuan), profil responden, dan kuesioner. Kuesioner dalam penelitian terdiri dari dua bagian, bagian yang pertama berisi faktor risiko yang tidak dapat dikontrol yaitu usia, riwayat keluarga, dan jenis kelamin, sedangkan bagian yang kedua faktor risiko yang dapat dikontrol yaitu kebiasaan konsumsi kopi, merokok, konsumsi alkohol dan obesitas. Kuesioner yang digunakan dalam penelitian ini diadaptasi dari penelitian yang dilakukan oleh Kakalang (2015), dengan menambahkan variabel independen merokok, konsumsi kopi, dan alkohol yang di uji validitas dari expert atau parah ahli. 
Analisis bivariat digunakan untuk melihat hubungan antara variabel independen dengan variabel dependen. Variabel independen dalam penelitian ini adalah usia, jenis kelamin, riwayat keluarga dengan hipertensi, konsumsi kopi, merokok, konsumsi alkohol dan obesitas. Variabel dependen adalah kejadian hipertensi yang dikategorikan menjadi hipertensi atau tidak hipertensi, dimana termasuk ke dalam data kategori nominal, dengan demikian uji statistik nonparametrik yang digunakan adalah uji Chi Square pada komputer yang terinstall software Statistical Product and Service Solution (SPSS).

Pengambilan keputusan hasil analisis data penelitian didasarkan pada tingkat signifikansi 95\% ( $\alpha$ 5\%) yaitu apabila $p$ value $\leq 0,05$ maka terdapat hubungan yang signifikan antara variabel independen dan dependen. Odds Ratio (OR) digunakan untuk mencari perbandingan kemungkinan peristiwa terjadi dalam suatu kelompok dengan kemungkinan hal yang sama terjadi di kelompok lain. Odds Ratio adalah ukuran mencari besarnya efek, untuk menarik kesimpulan nilai Odds Ratio menurut Sujareweni (2015) dapat dilihat apabila nilai $\mathrm{OR}>1$ artinya mempertinggi risiko, $\mathrm{OR}=1$ artinya tidak terdapat asosiasi/hubungan, dan $\mathrm{OR}<1$ artinya mengurangi risiko.

Langkah-langkah pengukuran tekanan darah menurut Andersen (2009) yaitu:

Step 1- Pilih peralatan yang tepat yang akan dibutuhkan dalam pengukuran (sthethoscope yang berkualitas, ukuran manset tekanan darah yang tepat, sphygmomanometer aneroid).

Step 2- Persiapkan responden: pastikan pasien dalam keadaan rileks dengan memberi waktu 5 menit sebelum pengukuran tekanan darah. Posisi pasien duduk tegak dengan posisi lengan sejajar dengan jantung dan kaki menapak sejajar dengan lantai. Pastikan pasien untuk tidak berbicara selama pengukuran berlangsung.

Step 3- Pilih ukuran manset yang tepat. Bungkus manset di sekitar lengan pasien dan gunakan garis indeks untuk menentukan apakah lengan berada di dalam area jangkauan, jika tidak pilih yang sesuai.

Step 4- Tempatkan manset di lengan pasien: palpasi lokasi brachial artery dan posisikan manset sehingga penanda arteri mengarah ke brachial artery, selanjutnya bungkus manset dengan pas di sekitar lengan.

Step 5- Posisikan sthethoscope: palpasi lengan di antecubical fossa (lipatan lengan) dan lokasikan di nadi yang teraba kuat dan tempatkan bell dari sthethoscope di brachial artery.

Step 6- Memompa manset: awali memompa manset dengan mendengar denyut nadi. Ketika manset sudah cukup dipompa, hentikan dan turunkan dengan perlahan dan dengar melalui sthetchoscope.

Step 7- Perlahan menurunkan manset: turunkan secara perlahan 2-3 mmHg per detik, jika terlalu cepat pengukuran tidak akurat.

Step 8- Dengarkan pembacaan sistolik: bunyi yang pertama terdengar melalui arteri disebut tekanan sistolik.

Step 9- Mendengar diastolik: lanjutkan dengan mendengar tekanan perlahan terdengar memudar dan ketika bunyi berhenti itu yang disebut dengan diastolik.

Step 10- Dua kali pemeriksaan untuk keakuratan: pengukuran dilakukan paling sedikit dua kali atau lebih baik tiga kali pengukuran dalam satu waktu dan apabila melakukan pemeriksaan di rumah, waktu yang 
baik adalah pagi hari sebelum minum obat dan malam hari sebelum tidur (Yahya, 2010). Data tekanan darah yang digunakan adalah rata-rata pagi dan malam baik sistol maupun diastol.

\section{Hasil dan Pembahasan}

Hasil analisis dan interprestasi data penelitian mengenai faktor-faktor yang berhubungan dengan hipertensi pada masyarakat non-Advent di Desa Tulusan Kecamatan Tagulandang dapat dilihat pada tabel 1 .

Tabel 1. Hasil Analisis Data Variabel

\begin{tabular}{lcc}
\hline \multirow{2}{*}{ Variabel } & \multicolumn{2}{c}{ Hipertensi } \\
\cline { 2 - 3 } & $\begin{array}{c}\text { OR } \\
(\mathbf{9 5 \%} \mathbf{C I})\end{array}$ & p-value \\
\hline Merokok & 1,366 & 0,403 \\
Alkohol & $(0,739-2,525)$ & \\
Obesitas & 1,983 & \\
& $(1,040-3,781)$ & 0,053 \\
Konsumsi kopi & 3,209 & \\
Riwayat keluarga & $1,865-5,521)$ & 0,000 \\
Jenis Kelamin & 0,858 & \\
& $(0,499-1,477)$ & 0,680 \\
Usia & 1,928 & \\
& $(0,114-3,337)$ & 0,026 \\
\hline
\end{tabular}

Hasil analisis data dalam tabel 1 . menunjukkan tidak ada hubungan yang signifikan antara merokok dengan hipertensi dengan nilai signifikansi 0,403 ( $p$ value $>0,05$ ). Menurut Lingga (2012) merokok mengandung berbagai senyawa beracun yang dapat mengganggu pengaturan tekanan darah, akibat racun rokok yang menembus dalam sel. Merokok dapat meningkatkan tekanan darah melalui zat nikotin yang terhisap dan masuk ke pembuluh darah sampai ke otak yang memberikan sinyal mengeluarkan hormon adrenalin.
Hormon adrenalin dapat membuat pembuluh darah menyempit dan meningkatkan beban kerja dari jantung, sehingga jantung memompa lebih keras (Marliani dan Tantan, 2013).

Berdasarkan penelitian yang dilakukan peneliti di Desa Tulusan, didapatkan bahwa tidak ada hubungan yang signifikan antara merokok dengan hipertensi, berarti responden yang merokok dengan yang tidak merokok relatif sama memiliki risiko hipertensi. Hal ini mungkin dikarenakan aktifitas fisik dan makanan yang dikonsumsi responden yang merokok lebih baik dibandingkan dengan responden yang tidak merokok. Merokok bukanlah penyebab pasti dari hipertensi, melainkan merokok adalah salah satu pemicu hipertensi. Bagi yang tidak hipertensi berhenti merokok dapat menurunkan risiko terkena hipertensi, sedangkan bagi hipertensi berhenti merokok dapat menurunkan tekanan darah dan risiko serangan jantung, dan bagi yang mengonsumsi obat hipertensi berhenti merokok dapat membantu kerja obat menjadi lebih efektif. Berhenti merokok adalah sebuah keputusan yang bijaksana untuk mengurangi risiko terkena hipertensi dan komplikasi lainnya.

Berdasarkan hasil analisis data dalam tabel 1. antara konsumsi alkohol dengan hipertensi diperoleh nilai signifikansi 0,053 ( $p$ value $>0,05$ ) artinya tidak ada hubungan yang signifikan antara konsumsi alkohol dengan hipertensi pada masyarakat non-Advent di Desa Tulusan Kecamatan Tagulandang. Hasil penelitian yang telah dilakukan peneliti di Desa Tulusan menunjukkan responden yang mengonsumsi alkohol dengan yang tidak mengonsumsi alkohol relatif sama berisiko terkena hipertensi. Hal ini mungkin dikarenakan aktifitas fisik dan makanan yang dikonsumsi 
responden yang mengonsumsi alkohol lebih baik dibandingkan dengan yang tidak mengonsumsi alkohol, sehingga responden mempunyai risiko yang relatif sama menderita hipertensi. Menurunnya jumlah masyarakat yang mengonsumsi alkohol dikarenakan program kesehatan dari pusat mengenai 12 indikator keluarga sehat.

Tabel 1. menunjukkan hubungan antara obesitas dengan hipertensi diperoleh nilai signifikansi $0,000(p$ value $<0,05)$ dan diperoleh $\mathrm{OR}=3,209$ artinya pada responden obesitas mempunyai risiko 3,2 kali lebih tinggi mengalami hipertensi dibandingkan dengan yang tidak obesitas. Obesitas (kegemukan) sudah terbukti menyebabkan daya pompa jantung dan sirkulasi volume darah lebih tinggi, jika dibandingkan dengan orang yang memiliki berat badan normal (Sunanto, 2013). Menurut Sudargo, Freitag, Rosiyani, \& Kusmayanti (2014) peningkatan tekanan darah terjadi seiring meningkatnya IMT (Indeks Masa Tubuh) dan hal ini disebabkan oleh distribusi lemak dalam tumbuh. Semakin berat badan seseorang kecenderungan kolestrol Low-Density Lipoprotein (LDL) lebih tinggi, LDL yang berlebihan akan menyebabkan timbunan lemak berlebih di pembuluh darah, yang menyempit dan kemudian mengeras (Kingham, 2009).

Hasil penelitian ini sejalan dengan penelitian yang dilakukan oleh Ramadhani dan Sulistyorini (2018), menunjukkan bahwa terdapat hubungan yang signifikan antara hipertensi dan obesitas dengan nilai $\mathrm{p}$ value $=0,001<$ 0,05 . Berdasarkan hasil penelitian yang dilakukan oleh Hendro, Hasibuan dan Natalia (2015) juga terdapat hubungan yang signifikan antara obesitas dengan hipertensi yaitu $\mathrm{p}$ value $=0,001<0,005$, dimana orang dengan obesitas memiliki risiko 2,2 kali lebih besar dibandingkan dengan tidak obesitas.

Hasil uji statistik pada tabel 1 menunjukkan juga tidak ada hubungan yang signifikan antara konsumsi kopi dengan kejadian hipertensi dimana nilai signifikansi $0,680 \quad(p$ value $>0,05)$. Kadungan kafein di dalam kopi dapat meningkatkan tekanan darah dalam waktu sementara, namun jika sensitif terhadap kafein sebaiknya menghindari konsumsi kopi untuk mencegah terjadinya hipertensi (Prasetyaningrum, 2014).

Berdasarkan penelitian yang dilakukan oleh peneliti di Desa Tulusan, tidak ada hubungan antara konsumsi kopi dengan hipertensi. Ini dikarenakan kopi bukanlah penyebab tunggal hipertensi, melainkan kopi adalah faktor pemicu timbulnya hipertensi. Pada saat melakukan penelitian, beberapa bulan sebelumnya masyarakat sudah mendapatkan penyuluhan kesehatan dari pelayanan masyarakat Puskesmas Tagulandang yaitu Program Indonesia Sehat-Pendekatan Keluarga (PIS- PK). Program dari PIS-PK adalah mengetahui 12 indikator utama untuk penanda status kesehatan sebuah keluarga, jika terdapat salah satu indikator kesehatan dalam sebuah keluarga, maka akan diberikan penjelasan kesehatan secara mendetail. Hasil wawancara dengan salah satu pegawai kesehatan yang ada di Puskesmas Tagulandang, program ini dilakukan dengan membangun komunikasi yang baik bersama keluarga dengan memberikan penjelasan mengenai informasi kesehatan, khususnya bagi keluarga yang memilik hipertensi diberikan penyuluhan tentang faktor-faktor pemicu hipertensi salah satunya adalah untuk dapat mengurangi atau berhenti konsumsi kopi. 
Hasil uji statistik pada tabel 1 . menunjukkan ada hubungan yang signifikan antara riwayat keluarga dengan kejadian hipertensi dengan nilai signifikansi 0,026 ( $p$ value $<0,05)$ ). Kemudian dari hasil analisis juga diperoleh $\mathrm{OR}=1,928(95 \% \mathrm{CI}: 1.114-$ 3,337 ) artinya responden yang memiliki riwayat keluarga hipertensi mempunya risiko 1,9 kali lebih tinggi mengalami hipertensi dibandingkan dengan responden yang tidak ada riwayat keluarga hipertensi. Hipertensi bisa diturunkan pada anak yang salah satu dari orangtuanya mengidap hipertensi dengan risiko $25 \%$ menderita hipertensi, sedangkan jika kedua orangtua hipertensi, $\quad 60 \% \quad$ keturunanya mendapatkan hipertensi (Sutomo, 2008). Menurut Muslimin \& Adiningsih, (2017) faktor riwayat keluarga dengan hipertensi akan meningkatkan risiko hipertensi, hal ini berhubungan dengan peningkatan kadar natrium intraseluler atau adanya gen yang berhubungan dengan kejadian hipertensi. Hasil penelitian ini sejalan dengan penelitian yang dilakukan oleh Azhari (2017) dimana hasil analisis chi-square didapatkan $p$ value $=0,002<\alpha(0,05)$, berarti ada hubungan yang signifikan antara riwayat keluarga dengan kejadian hipertensi, dengan nilai Odds ratio (OR) $=3,686$, berarti responden yang mempunyai riwayat keluarga hipertensi berisiko 3,6 kali terkena hipertensi dibandingkan dengan responden yang tidak mempunyai hipertensi.

Berdasarkan hasil penelitian dari peneliti di Desa Tulusan didapati sebagian besar responden hipertensi memiliki keluarga dengan riwayat hipertensi. Hal ini menunjukkan riwayat keluarga dengan hipertensi dapat memicu terjadinya hipertensi. Riwayat keluarga bukanlah faktor penyebab utama hipertensi, tapi itu merupakan faktor pemicu. Riwayat keluarga hipertensi mungkin merupakan faktor risiko yang tidak dapat diubah, tapi yang perlu diperhatikan adalah ada faktor-faktor lain yang dapat diubah untuk menurunkan risiko hipertensi, yaitu dengan merubah gaya hidup untuk menjadi lebih sehat.

Tidak ada hubungan yang signifikan antara jenis kelamin dengan kejadian hipertensi dengan nilai signifikansi 0,121 ( $p$ value $>0,05$ ). Perbedaan jenis kelamin merupakan salah satu faktor pencetus kejadian hipertensi pada waktu yang berbeda, hal ini disebabkan perbedaan hormon yang bekerja pada masing-masing individu. Namun, hasil penelitian yang dilakukan oleh peneliti di Desa Tulusan menunjukkan tidak ada hubungan yang signifikan antara jenis kelamin dengan hipertensi. Hal ini berarti responden yang berjenis kelamin perempuan dan laki-laki yang berada di Desa Tulusan memiliki risiko hipertensi relatif sama. Jenis kelamin bukanlah penyebab langsung hipertensi melainkan ada kebiasaan yang tidak sehat yang dapat meningkatkan risiko hipertensi, sehingga jangan berfokus pada satu faktor saja, karena ada begitu banyak faktor yang dapat meningkatkan risiko hipertensi.

Terdapat hubungan yang signifikan antara usia dengan hipertensi dengan nilai signifikan 0,000 ( $p$ value $<0,05)$ danh $\quad \mathrm{OR}=12,583 \quad(95 \% \mathrm{CI}: \quad 4,398-$ 36,001 ) artinya pada usia $\geq 40$ tahun mempunyai risiko 12,5 kali lebih tinggi mengalami hipertensi dibandingkan dengan usia $<40$ tahun. Faktor usia sangat berpengaruh karena pada usia lanjut pembuluh darah cendrung kaku dan elastisitasnya berkurang (Agromedia, 2009). Hasil penelitian ini sejalan dengan penelitian yang dilakukan oleh Artiyaningrum dan Azam (2016) menunjukkan bahwa ada hubungan yang signifikan antara usia dengan kejadian hipertensi tidak 
terkendali ( $\mathrm{p}$ value $=0,022<0,05$ ) dan hasil analisis diperoleh nilai $\mathrm{OR}=2,956$, artinya responden yang memiliki usia $>40$ tahun memiliki risiko 2,956 kali mengalami tekanan darah tinggi. Hasil penelitian ini juga didukung oleh hasil penelitian peneliti sebelumnya yaitu Kakalang (2015) menunjukkan ada hubungan yang signifikan antara usia dengan kejadian hipertensi primer pada anggota gereja Advent dengan nilai $\mathrm{p}=$ $0,003<0,05$, dan anggota yang berusia $>40$ tahun memiliki kecendrungan mengalami hipertensi 5 kali dibandingkan dengan yang berusia $<40$ tahun.

Berdasarkan penelitian yang dilakukan oleh peneliti di Desa Tulusan melalui pembagian kuesioner dan pengukuran tekanan darah, didapati ada cukup tinggi masyarakat yang berusia $\geq 40$ tahun mengalami hipertensi. Penelitian ini menunjukkan, seiring bertambahnya usia maka elastisitas dari pembuluh darah akan berkurang atau kaku yang akan mengakibatkan tekanan darah meningkat. Usia bukan satu-satunya faktor pencetus hipertensi, pola hidup tidak sehat pun dapat meningkatkan risiko hipertensi. Pola hidup yang sehat dapat dipersiapkan sejak muda, sehingga di masa tua nanti risiko pencetus hipertensi tidak akan berisiko tinggi.

\section{Kesimpulan dan Rekomendasi}

Terdapat hubungan yang signifikan antara usia, riwayat keluarga, obesitas dengan hipertensi primer pada masyarakat Non-Advent di Desa Tulusan Kecamatan Tagulandang, sedangkan jenis kelamin, konsumsi kopi, merokok, konsumsi alkohol tidak memiliki hubungan yang signifikan.

Bagi tenaga kesehatan setempat dapat lebih memahami strategi promosi kesehatan dalam jupaya meningkatkan derajat kesehatan masyarakat telebih dalam hal hipertensi. Bagi masyarakat di Desa Tulusan Kecamatan Tagulandang diharapkan dapat memperhatikan pola hidup sehat, terlebih khusus dalam hal menjaga berat badan ideal sehingga mengurangi risiko hipertensi. Penelitian sejenis selanjutnya dapat menggunakan rancangan penelitian yang berbeda seperti studi kasus kontrol atau kohort, dengan jumlah variabel tertentu, seperti faktor stress sebagai faktor risiko hipertensi.

\section{Referensi}

Agromedia. (2009). Solusi sehat mengatasi hipertensi. PT Agromedia Pustaka: Jakarta.

Andersen, K. (2009, July). 10 Steps to accurate manual blood pressure measurement. Diakses dari http://www.suntechmed.com/blog/ entry/4-bp-measurement/42-10step-to-accurate-manual-bloodpressure-measurement

Ansar, J., Dwinata, I., \& Apriani, M. (2019). Determinan Kejadian Hipertensi Pada Pengunjung Posbindu Di Wilayah Kerja Puskesmas Ballaparang Kota Makassar. Jurnal Nasional Ilmu Kesehatan, 1(3), 28-35.

Azhari, M. H. (2017). Faktor-faktor yang berhubungan dengan kejadian hipertensi di puskesmas makrayu kecamatan ilir barat II palembang. Aisyah: Jurnal ilmu kesehatan vol 2.

Bell, K., Twiggs, J., \& Olin, B. R. (2015). Hypertension: the silent killer: updated jnc-8 guideline 
recommendations. Diakses dari https://cdn.ymaws.com/www.apar x.org/resource/resmgr/CEs/CE_Hy pertension_The_Silent_K.pdf

Hendro, Hasibuan, P., \& Natalia, D. (2015). Hubungan obesitas dengan hipertensi pada penduduk kecamatan sintang kalimantan barat. eJournal Kedokteran Indonesia, Vol 36 No 2.

IFMSA (2017). Policy noncommunicable diseases. Diakses dari http://ifmsa.org/noncummunicable-diseases/

Kakalang, C. J. (2015). Faktor Risiko Terjadinya penyakit hipertensi pada anggota gereja masehi Advent hari ketujuh (GMHK) di pulau tagulandang (skripsi). Airmadidi: Universitas Klabat

Kemenkes (2014). Situasi kesehatan jantung. Diakses dari http://www.depkes.go.id/article/vie w.15021800003/situasijantung.html

Kemenkes [Kementrian Kesehatan] RI. 2018. Manajemen Program Pencegahan dan Pengendalian dan Perhitungan Pencapaian SPM Hipertensi. Jakarta.

Kingham, K. (2009). Makan oke hidup oke dengan kolesterol tinggi. Jakarta: Erlangga.

Marliani, L., \& Tantan, H. S. (2013). 100 Question and answer hipertensi. Jakarta: PT Gramedia.

Oktaviarini E. Hadisaputro S, Ari Suwando, Henry Setyawan. 2019. Faktor yang berisiko terhadap hipertensi pada pegawai di wilayah Perimeter Pelabuhan
(Studi diKantor Kesehatan Pelabuhan Kelas II Semarang). Jurnal Epidemiologi Kesehatan Komunitas, 4(1): 35-44.

Prasetyaningrum, Y. I. (2014). Hipertensi bukan untuk ditakuti. Jakarta: Fmedia (Imprint AgroMedia Pustaka).

Ramadhani, E. T., \& Sulistyorini, Y. (2018). Hubungan kasus obesitas dengan hipertensi di provinsi jawa timur tahun 2015-2016. Jurnal Berkala Epidemiologi.

Sudargo, T., Freitag, H., Rosiyani, F., \& Kusmayanti, N. A. (2014). Pola makan dan obesitas. Yogyakarta: Gadjah Mada University Press.

Sunanto, H. (2013). 100 Resep sembuhkan hipertensi, obesitas, dan asam urat. Jakarta: PT Elex Media Komputindo.

Susanti, N., Siregar, P. A., \& Falefi, R. (2020). Determinan kejadian hipertensi masyarakat pesisir berdasarkan kondisi sosio demografi dan konsumsi makan. Jurnal Ilmiah Kesehatan, 2(1), 4352.

https://core.ac.uk/download/pdf/32 2601058.pdf

Wulandari, S. (2020). Determinan Hipertensi Pada Sopir Angkutan Umum Jurusan JonggolCileungsi, Kabupaten Bogor. In Prosiding Seminar Nasional Kesehatan Masyarakat 2020 (Vol. 1, No. 1, pp. 1-17).

Yahya, F. (2010). Menaklukan pembunuh no.l: mencegah dan mengatasi penyakit jantung koroner secara tepat dan cepat. Bandung: qanita. 